\title{
Communicating Seismic Risk: the Geoethical Challenges of a People-Centred, Participatory Approach
}

\author{
IAIN S. STEWART \\ JOHANNA ICKERT \\ Sustainable Earth Institute, University of Plymouth, United Kingdom \\ iain.stewart@plymouth.ac.uk \\ johanna.ickert@plymouth.ac.uk \\ ROBIN LACASSIN \\ Institut de Physique du Globe de Paris, Sorbonne Paris Cité University, CNRS, France \\ lacassin@ipgp.fr
}

\begin{abstract}
The Sendai Framework for Disaster Risk Reduction (SFDRR) encourages scientists to participate in bottom-up risk communication approaches that directly engage hazard-prone populations. Effective communication of seismic risks not only has economic impacts in terms of hazard mitigation but also provides social value in potentially empowering the marginalized populations that disproportionately live in high-risk areas. This emphasis on community-focused disaster preparedness, however, presents a novel set of communication challenges for geoscientists. Few scientists have training in or experience of translating their science for lay publics, and conveying complex risk information is especially difficult in circumstances where scientific issues are socially contested and politically charged. Recognising that disaster threats can create troublesome information battlegrounds, this paper explores the ethical and practical aspects of seismic risk communication, motivated by an early-career earth scientists' workshop in Istanbul that voiced the concerns of young geoscientists confronted firsthand by at-risk publics. Those concerns form the basis of a wider review of the risk communication issues that are likely to be encountered if community-centred participatory DRR approaches are to be adopted by earthquake science researchers.
\end{abstract}

\section{INTRODUCTION}

' $T$ here has to be a broader and a more people-centred preventive approach to disaster risk. Disaster risk reduction practices need to be multi-hazard and multi-sectoral, inclusive and accessible in order to be efficient and effective. (...) There is a need for the public and private sectors and civil society organizations, as well as academia and scientific and research institutions, to work more closely together and to create opportunities for collaboration.' (Sendai Framew ork, 2015, p.7).
The Sendai Framework for Disaster Risk Reduction (SFDRR) offers a new global instrument for confronting natural hazards, setting out an ambitious holistic strategy that embraces the need for a '... full and meaningful participation of relevant stakeholders at appropriate levels' and the '... empowerment and inclusive, accessible and non-discriminatory participation of the most marginalised publics' (UNISDR, 2015). As such, the Sendai Framework defines a new social contract between the hazard scientist and the wider public (Ismail-Zadeh et al., 2017). It is a 
contract that encourages the scientific community to endeavour, alongside their existing technical expertise, to '... support action by local communities and authorities; and support the interface between policy and science for decision-making' (UNISDR, 2015). This vision of citizen-oriented research is mimicked in other areas of geosocietal concerns, such as energy, climate change and infrastructure development (e.g. Pidgeon et al., 2014; Kamlage and Nanz, 2017), and is one increasingly endorsed by major international sponsors of scientific research. The European Commission, for example, changed the title of their 'Science and Society' programme to 'Science in Society' and under Horizon 2020 developed guidelines around 'Responsible Research and Innovation' (RRI) with the deliberate goal of stimulating reflexivity and involving a range of social actors - scientists, citizens, politicians and businesses - more closely in scientific endeavours that were codesigned and co-produced by society (Owen et al., 2012).

Inherent in this shift from the conventional 'top-down', 'expert-led' approach to the emergent 'bottom-up', 'community-led' approach is the challenge of 'the last mile' - a term borrowed from the telecommunications sector, in which the final connection between the consumer and the technology determines how effective it is for the vast market of users. The challenge of reaching the last mile (in this case, reaching those people directly at risk) has become a critical notion that increasingly informs our thinking about a far wider range of natural risk challenges (e.g. Shah, 2006), although in keeping with the shift to a people-centred focus of disaster risk reduction discourse it has become re-framed as 'the first mile' (e.g. Kelman and Glanz, 2014; Baudoin et al., 2016).

In addition to informing civic officials and disseminating to policy makers, communicating that first mile to reach the people who directly face extreme hazard threats ought to be a fairly uncontentious component in hazard preparedness and mitigation efforts. Yet, a participatory approach marks a methodological move away from the prevailing mode of knowledge transfer towards more inclusive transdisciplinary strategies that incorporate peer-role models, adopt social network-based strategies and di- rectly engage with communities in motivating preparedness actions (Schneidewind et al., 2016; Schlosser and Pfirman, 2012; Drake et al., 2015; Bendito and Barrios, 2016; Ismail-Zadeh et al., 2017). This new, transdisciplinary science has been controversial (Schneidewind and Brodowski, 2014) and there are currently no guidelines for what constitutes successful participation and what measures promote building trust between civil society and its organizations and science. Despite the international push for participatory approaches, there is a lack of social spaces and interactive formats that enable exchange and joint learning between technical specialists and lay publics. A review of people-centred approaches for disaster risk management described:

'... a complex landscape characterized by insufficient resources at the local level, and lack of willingness among the public at risk to share responsibility for disaster risk management with authorities. If official authorities are to implement the new people-centred approach, they must better understand residents' perspectives and responsibility expectations, become more competent communicators, and be willing to engage in long-term dialogue with communities' (Scolobig et al., 2015, p.202).

The challenge of how to communicate effectively to at-risk communities, therefore, lies at the heart of the people-centred approach to disaster risk reduction. Despite this, few geoscientists have been trained in conveying their technical know-how beyond the academic and professional world, and, for those that have, that training usually prioritises peer-to-peer communication skills and how to manage relations with journalists and better access the broader print and broadcast media (Liverman 2008). In contrast, ordinary people 'on the ground' - from local community groups to civic authorities - tend to be less familiar and more remote (i.e. harder-to-reach) audiences for most scientists (Liverman 2008, Stewart and Nield 2013).

In addition to being 'harder to reach', public audiences often meet 'science' at times of crisis. In emergency situations, scientific understandings built up gradually over many decades are expected to be delivered by 'experts' in neat 
media sound-bites and unambiguous public statements (Stew art and Nield, 2013). Distilling complex technical knowledge into digestible popular risk messages that can be readily consumed by lay audiences is a persistent challenge for those working at the science/ public interface. In the immediacy of an emerging disaster, people tend to behave in ways and make decisions that are not anticipated by scientific experts and by emergency managers.

Outside of crisis situations, communicating uncertainty to at-risk publics is associated with several challenges, such as identifying the facts relevant to recipients' decisions while determining the relevant uncertainties, estimating their impact, formulating possible messages, and evaluating their success (Fischhoff and Davis, 2014). In addition, building community awareness of potential risks can also be difficult if people hold serious misconceptions about basic science concepts, if the scientific issues are socially contested, and if the hazard threat is politically charged (Stew art and Lew is 2017).

The result is that the science/ public knowledge interface can quickly become more like the frontline of an information battlefield. In such combative circumstances, those conveying the risk of natural hazards to communities threatened by them can find themselves navigating a careful communication course between the technical nuances and uncertainties of extreme natural events on the one side and the normative nuances and uncertainties of media practice and human behaviour on the other.

The dilemmas faced by geoscientists in communicating risk during seismic crises have been most extensively documented and acutely dissected for the 2009 L'Aquila (Italy) earthquake and subsequent legal trial (Alexander, 2010 and 2014; Marzocchi, 2012; Jordan, 2013; Di Capua and Peppoloni, 2014; Dolce and Di Bucci, 2014; Mucciarelli, 2014; Yeo, 2014; Cocco et al., 2015; DeVasto et al., 2016). Although initially framed as a trial of scientists who 'failed' to predict an earthquake, it is more widely interpreted as a failure in risk communication, as Oreskes (2016, p.254) notes:

'The case centered not on the matter of whether or not earthquakes can be predicted, but on political questions about the social obligations of scientists speaking in official advisory capacities, and epistemic questions about the appropriate manner in which risk assessments should be performed. The questions at stake were what information scientists should have offered the public, and how that information should have been communicated. They were not so much matters of scientific facts, but matters of how those facts were rendered and communicated.'

Such 'faulty' communications arose because seismic crises are not simply geophysical phenomena but they are also socio-political incidents. Their threat can motivate vested business interests to oppose the science (Geschwind, 1997 and 2011) and their incidence can be catalysts of cultural change or triggers for political upheaval (Clancey, 2006). As is evident in other areas of science, notably climate change discourse, conflicts of interest can result in 'manufactured uncertainty' and the deliberate obfuscation or misrepresentation of information for which there is broad scientific consensus (Michaels, 2005; Michaels and Monforton, 2006; Oreskes and Conway, 2007). In such contested social spaces, the wisdom and responsibility of geoscientific experts in offering guidance or advocacy has been questioned:

'Whether scientists providing expert input into policy issues should be guided by extra-scientific values (and if so, whose values, and which values) in either the conduct or communication of their science, and even whether they should go beyond their scientific competence strictly speaking and provide advice about policy options, is open to debate' (Yeo 2014).

This societal entanglement has potentially transformative implications for the geoscientists that study them, as acknowledged by Oreskes (2016, p.261):

'Earthquake safety has never been simply a matter of geophysics, but most earthquake scientists ... have traditionally understood their job to be to study how, when, and why earthquakes happen, and only to a lesser extent (if at all) how to communicate that knowledge to engineers and officials responsible for mitigation, or to the general public ... But in the contemporary world, the inter-relationship between knowledge and safety is not easily disentangled. 
Seismology is no longer simply a matter of geophysics, if it ever was. It involves consideration of ethics, values, and monetary and social costs. L'A quila shows that scientists can no longer ignore the social factors that affect and even control how damaging a particular earthquake may be. Earthquake prediction is a social science.'

In this paper, we carry forward Oreskes's provocation that earthquake science is a social science by considering the issue of how to communicate seismic risk in a public sphere in which the science is socially contested and politically charged. Our consideration arises not from Italy but from Istanbul, another troublesome earthquake hot spot, and viewed not from the perspective of senior hazard specialists but instead from that of early-career geoscientists. Motivated by their emergent concerns, we examine key themes of risk communication that might be important if neighbourhood-based participatory DRR is to be adopted by the earthquake science community.

\section{CASESTUDY:A SEISMIC CONFRONTATION IN ISTANBUL}

Istanbul, a mega-city of 14.5 million residents, faces a major earthquake threat (Hori et al., 2017). Over the last century, a westward- migrating sequence of large earthquakes has left one prominent segment of the North Anatolian Fault unruptured (Armijo et al., 1999; Stein et al., 1997; Le Pichon et al., 2003). That segment lies immediately south of the city, beneath the waters of the Marmara Sea and seismologists expect this seismic gap to be filled by a $\mathrm{M}>7$ earthquake in the coming decades (Parsons et al., 2000; Parsons, 2004; Bohnhoff et al., 2013). The lethality of the threat is evident from a destructive earthquake that struck to the east of Istanbul in August 1999, killing 17,000 people and making approximately half a million people homeless (Özerdem, 1999). Risk scenarios for a future Marmara Sea earthquake anticipate significant fatalities and widespread damage to residential housing and urban infrastructure. For example, a future M 7.25 earthquake on this offshore segment is expected to heavily damage or destroy $2-4 \%$ of the near $1,000,000$ buildings in Istanbul, with $9-15 \%$ of the buildings receiving medium damage and $20-34 \%$ of the buildings lightly damaged (Erdik et al., 2011; Erdik, 2013). Shaken by the 1999 earthquakes, Istanbul's civic authorities attempted to address the acute seismic vulnerability of the city through a series of legislative

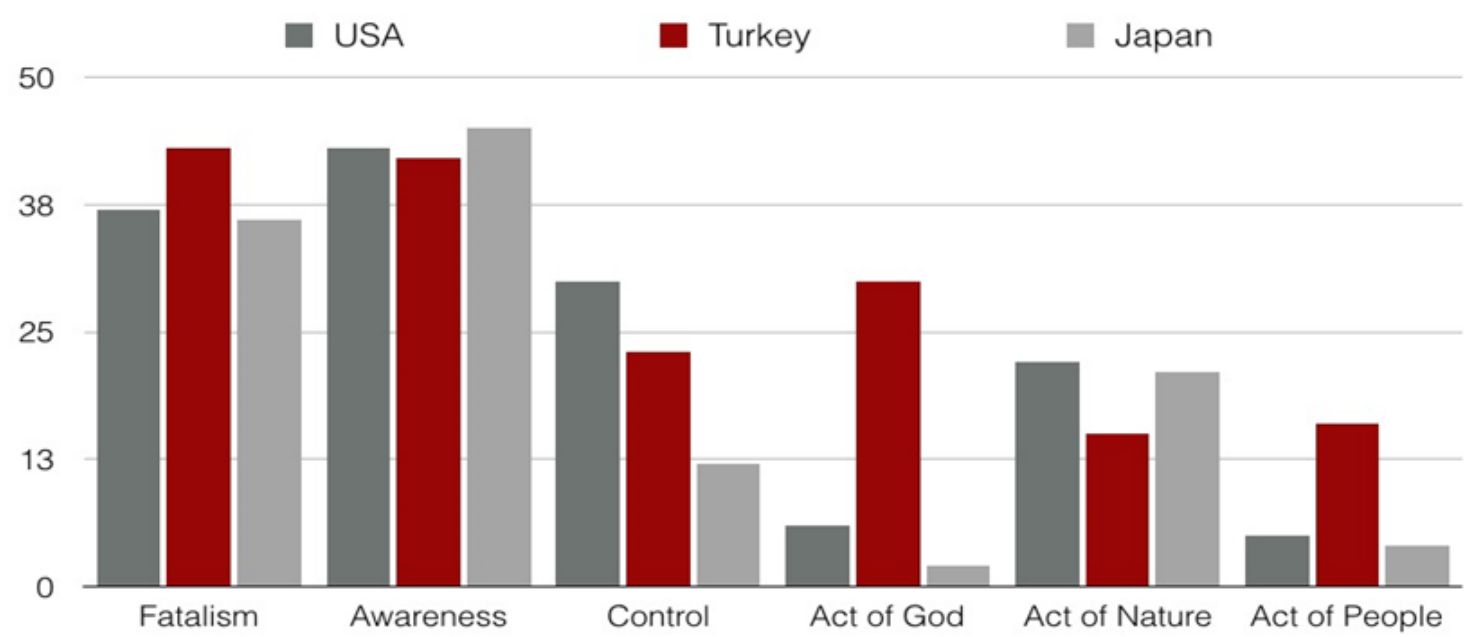

Figure 1: There is a strong cultural influence on people's perspectives on the perceived earthquake threat. Based on interviews with residents in earthquake-prone parts of USA, Japan and Turkey, most participants indicated a high awareness of seismic adjustment but there was much variation in belief about the levels of human agency and control. Turkish participants tended strongly toward fatalism, regarded earthquakes as divine providence but displayed a heightened focus on vulnerabilities caused by institutional and collective failings, implying that the consequences of earthquakes were largely determined by the actions of people and society. Redrawn from Joffe et al. (2013, figure 4). 
measures facilitating urban renewal. The controversial implementation of the 2005 renewal law No. 5366 in the city's historic districts authorised the central government housing development agency (TOKI) to undertake regeneration projects in seismically vulnerable gecekondu (squatter) neighbourhoods, projects that met significant local resistance (Karaman, 2008; Unsal, 2015). That resistance reflects legislative changes that have been imposed by civic authorities. In 2012, the urban regeneration law No. 6306 extended regeneration beyond the historic districts, targeting neighbourhoods that are generally not those most vulnerable to earthquake destruction but instead represent areas where redevelopment is highly economically profitable (Gibson and Gökşin, 2016). Despite a recognition that 'seismic risk in the buildings in Istanbul is mostly dominated by building vulnerability, not hazard' (Yakut et al., 2012, p.1533), there is widespread distrust of Istanbul's retrofitting and reconstruction measures even among residents of some of the city's most at-risk quarters (Green, 2008; Islam, 2010;
Karaman, 2013; Kuyucu, 2014).

The roots of this distrust go deep into the Turkish 'earthquake psyche'. A comparison of populations living in earthquake-prone areas in Japan, USA and Turkey revealed that especially strong and varied emotions permeate Turkish earthquake perceptions and attitudes (Joffe et al., 2013) (Fig. 1). Direct experiences with the 1999 earthquakes have provoked heightened feelings of worry, fear and anxiety, but in addition there were strong expressions of corruption and incompetence of politicians, civil servants, planning regulators and the construction industry (Fig. 2). For many, it was this endemic corruption, greed and selfishness that was seen to produce urban vulnerability, and in turn created a heightened sense of dissonance (fatalism) and weakened sense of control and selfefficacy. Thus, despite a substantial awareness of the earthquake risk, Joffe et al. (2013) report that Turkish respondents were far less likely than their US or Japanese equivalents to adopt seismic adjustment measures, a tendency also apparent in other studies (Rustemli and Karanci, 1999; Özerdem, 1999; Eraybar et al.,

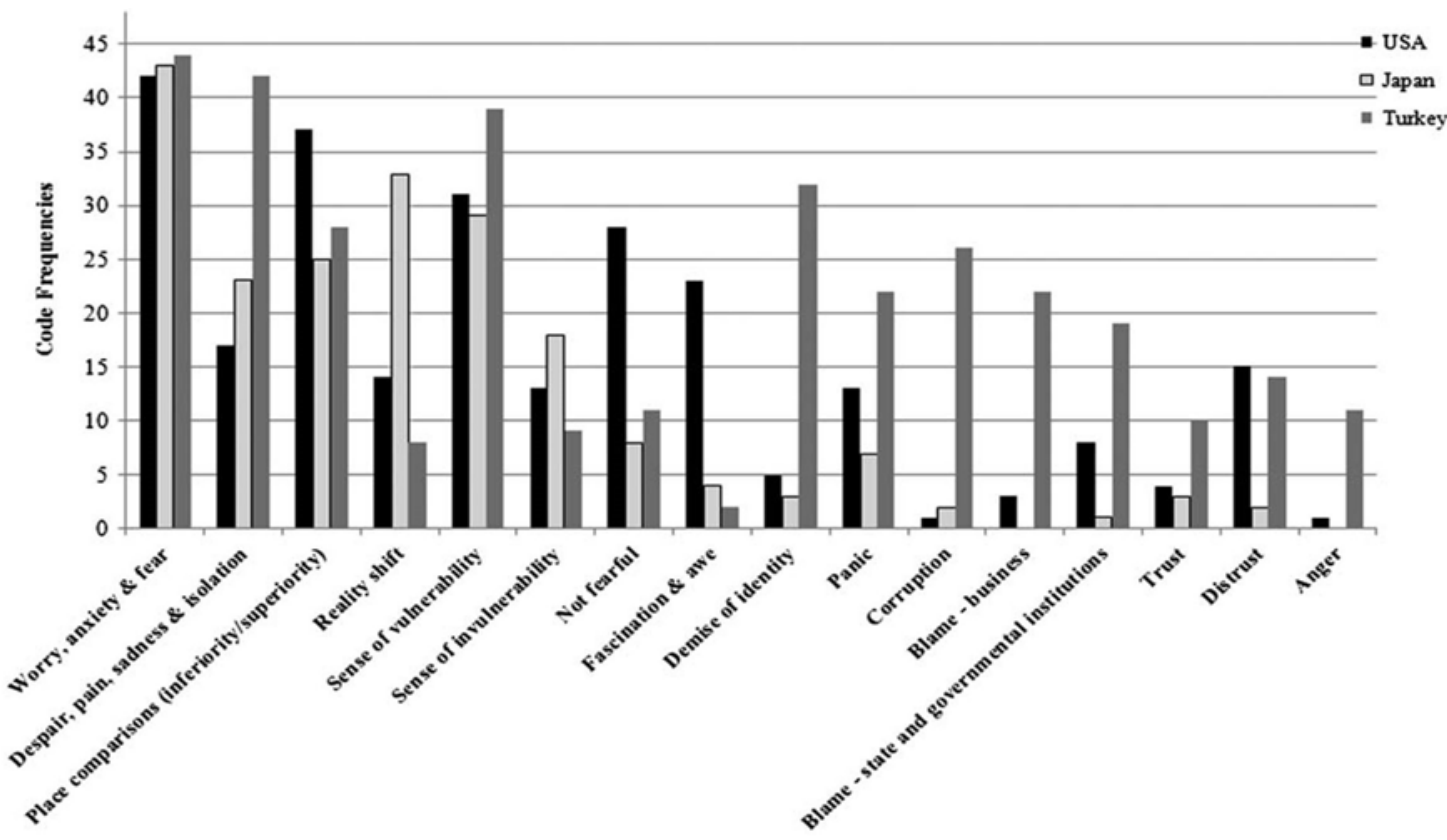

Figure 2: The emotional and moral responses of people to earthquakes vary in strength and character between three earthquake-prone countries - USA, Japan and Turkey. Fear and anxiety-related emotions dominate in all three countries, but Turkish participants show a greater prevalence of grief- and trauma- related emotions and display considerably more emotions relating to moral issues such as corruption (e.g., anger, distrust, blame). From Joffe et al. (2013, figure 3). 
2010; Tekeli-Yeşil et al., 2010a, 2010b, and 2011; Oral et al., 2015; Taylan, 2015). Indeed, Joffe et al. (2013) report that the Turkish respondents who felt themselves most vulnerable to earthquakes displayed the lowest adoption of antiseismic adjustment measures. In such a socially polarised and politically sensitive context, developing neighbourhood-based participatory strategies for seismic risk communication would appear difficult.

To explore this difficulty, a communication training workshop for early-career geoscientists held in Istanbul directly confronted twelve $\mathrm{PhD}$ and postdoctoral researchers with the overtly politicised nature of the Istanbul earthquake threat (Ickert and Stewart, 2016). As part of the workshop the young geoscientists visited at-risk neighbourhoods within the city to hear from residents and community leaders about how the city's seismic risk was manifest 'on the ground', witnessing firsthand the effects of the unpopular urban renewal transformation programme. Following this field provocation, Ickert and Stewart (2016) report how the workshop participants were invited to discuss their perceived role as communicators. Across the group of young researchers there was broad agreement on the relevance and importance of their expert knowledge reaching at-risk communities, but considerable discussion about the appropriate way and level of engaging with the public.

Researcher 1: If you know that something will happen [...] that many people could die [...] you will have to communicate that. You have to communicate that in order to prepare people.

Although this view was widely shared, much debate centred on the participants' individual understandings of the role and responsibility of geocommunicators, and what implications this had for their professional life. For some, the disincentives to communicating more widely were practical as well as moral:

Researcher 8: (...) It is our responsibility. But the problem is: We are not paid for that. We have to maintain a career as well. And this is only one of the little aspects that are very relevant. We have to do it for the sake of it. We do a lot of things for science which are for free. And we al- so have a hard time to maintain a pace...and to do publications, to find the next position and so on. So it is a very difficult balance.

Researcher 7: There is no real reward.

Researcher 8: Well, it depends on how you interpret reward.

Some participants found it crucial not to blur the boundary between scientists and nonscientists and to retain their role as "objective experts", feeling uneasy with the prospect of operating beyond the geoscience realm.

Researcher 11: I think you should do your best to improve your analyses and get proper results and publish and explain these results to proper people. For example, the government or the administration. And these people should know what to do with this. You can give them suggestions what you think is the best idea to use the results and how to protect the people, but the decision belongs to them.

Researcher 4: In my humble opinion, science has something to do with knowledge. Policies, hazard mitigation, those are things related to judgement, to decision-making. Those are two completely different things.

For some participants, a direct engagement with residents, particularly in politicized contexts, was considered as negatively affecting their role as scientists, potentially risking a loss of reputation, trust and scientific credibility due to actual or perceived advocacy positions. Others, whilst acknowledging these worries, stressed instead the 'moral and professional duty' to directly provide their expertise to communities, especially in situations where inhabitants face an acute risk and openly request closer collaborations with scientists. For them, there was a 'risk of losing public trust' when not reacting to shortcomings of communication, but at the same time an anxiety about drifting into the role of 'advocate' or even 'activist', as this exchange demonstrates:

Researcher 8: A hypothetical case, let's imagine the scientific community has a very clear view that the Marmara earthquake is going to happen in five years time, and it is going to be magnitude 8. Then what is your responsibility, when people are not reached by standard geoscience commu- 
nication? This is how I face this problem. Then you really have to push the boundaries and tell the people that they should move away from the boundary [...] but I am already in the activist part.

Researcher 2: You're looking at the human aspect, not at the scientific aspect. As a human being, when you see that something bad will happen very soon, then of course you will push people and try to fix the problem [...]. As a scientist you just have to do the research, get the information and share it.

Researcher 8: But I absolutely don't feel like this this is my scientific part and this is my human part [...] I don't understand why geoscience should be communicated in a very specific, narrow way, for example centred on geohazards. Then people might know something about the physics, but they don't really do anything in their daily lives. And this is the challenge.

Researcher 7: You could make sure that you inform the public better, so that they can find a way around this corrupt system so that people are informed to really make decisions.

Researcher 10: But this is really complicated.

This disagreement about roles and responsibilities of geoscientists in the risk communication process suggest that the multitude of factors that influence how risk communication is perceived, interpreted and translated by inhabitants of at-risk communities is equally recognised by scientists. Despite this, there was consensus among the group on the necessity to more effectively connect with at-risk communities in order to reduce their seismic vulnerability. In addressing this, however, there was uncertainty about whether the young geoscientists had the appropriate skillset to successfully engage with lay audiences. Some felt confident in this aspect, giving personal examples of science-public interactions, such as encounters with local residents in the course of their field work, incidents in which they "had to get information from local people", and were asked to "explain" what "they are doing". In that context, some support for the value of a more participatory approach emerged:
Researcher 6: Why do you think that only the geoscientists give the information? Maybe there are things that you don't know, and that only an ordinary person knows. For example when you go to the field, [...] to a little village, if you are working on a recent event of that region, you go to the manager of the village, and you talk to him, for example "Have you ever had any floods in this area?" It is a communication situation and you learn from a person that is not a geoscientist.

More generally, however, the researchers felt insufficiently skilled in communication to reach be-yond the academic and professional geoscience community. Interaction with lay audiences was judged a 'rather unknown territory'. Given this perceived skills deficit, debate emerged about whether it was more effective to 'pinpoint the communication talents' within the geoscience community or instead to engage in interdisciplinary research collaborations. Liaising with social scientists were proposed, as was working with intermediaries or translators - media representatives, NGOs or even artists to more effectively share knowledge with people on the ground. This brief exchange captures the essence of that disagreement:

Researcher 10: Our responsibility is to produce science and use other scientists who can talk to people, like anthropologists, sociologists or people who have studied philosophy, psychology, this kind of stuff... My point is that we need a bridge to communicate with the people. We cannot communicate directly. We need a translator.

Researcher 3: Or translate it ourselves.

Researcher 2: It won't be that easy for us.

The implications arising from these workshop discussions are examined in detail by Ickert and Stew art (2016), but here we highlight the basic dilemma: communicating directly with at-risk communities is recognised as being important but there was a general anxiety about how easily or effectively geoscientists can adopt such a participatory approach. In this regard, the early-career geoscientists raise critical questions about how best to integrate other disciplinary perspectives, particularly those from the social sciences, into their geo-risk ex- 
pertise. Stimulated by these methodological dialogues, the following sections summarise some key findings that have emerged from broader social science discourses on risk communication.

\section{FAULTY COMMUNICATIONS - TOWARDS A SOCIAL SCIENCE OF CON VEYING SEISMIC RISK}

\subsection{The Risk Perception Paradox}

'The majority of people at risk from earthquakes do little or nothing to reduce their vulnerability' (Solberg et al., 2010, p.1663).

The conventional way of communicating risk is through education campaigns that raise public awareness of hazard threats. This approach rests on the assumption that individuals or communities with high hazard awareness are more likely to respond to warnings and undertake preparedness measures than individuals or communities with a lower/ deficient hazard aw areness. Increase an individual's perception of a threat, the assumption goes, and you improve their preparedness. Demeritt and Norbert (2014) describe this approach to risk communication either under the term "risk message model", referring to the belief that sound risk communication is about faithfully transmitting risk information without distortion, or under the term of a "risk instrument model", a communication approach with the goal to elicit certain cognitive or behavioural responses in the target audiences that are addressed (Demeritt and Norbert, 2014). However, several decades of social science research indicates that there can be little or no correlation between the provision of scientific information about geophysical hazards and risks and the adoption of preparedness measures by individuals or communities (Palm and Hodgson, 1992; Palm, 1998; Spittal et al., 2008; Solberg et al., 2010; Wood et al., 2011). While the hazard scientist is steeped in probabilistic or deterministic thinking about the chances or impacts of an extreme event, the statistical likelihood of a disaster is barely taken into account when ordinary people make judgments about perceived risk levels, and the perceived magnitude of a disaster seems equally to be of little importance. Instead, there is a growing appreciation of the role of socio-cultural, cognitive and emotional variables in risk perception and behaviour. Solberg et al. (2010) provide a comprehensive review of how people think, feel and act about seismic risk adjustment, arguing that individual or collective aware-ness is shaped by a myriad of social factors, psychological biases and cultural norms, including experience, optimism, demographic characteristics (gender, age, status), perceptions of fate and fatalism, individual and community feelings of control, self-efficacy and empowerment, as well as the degree of trust in experts and authorities. All of these risk mediators are sensitive to cultural and political contexts, and all need to be considered if risk communication is to be truly effective.

The 'risk perception paradox' (Wachinger et al., 2013) contends that if risk perception is only loosely related to risk adjustment, then simply disseminating information on seismic hazard and societal vulnerability to exposed populations may not motivate meaningful risk reduction behaviour. This reappraisal rests on a broader rejection by communication practitioners of the over-reliance on factual information in conveying scientific issues to the public (Burns et al., 2003; Nisbet, 2009). After all, the 'facts' around complex scientific issues are often contested even by the experts, and the same technical problem can be presented in very different ways to elicit markedly contrasting responses. In the febrile atmosphere of natural emergencies and crisis situations it can be expected that 'facts will be repeatedly misapplied and twisted in direct proportion to their relevance to the political debate and decision-making' (Nisbet and Mooney, 2009, p.56), with the result that even '... compelling scientific information often runs aground almost as soon as it is launched into the choppy waters of public discourse' (Weber and Word, 2001, p.488).

The social psychology of how people receive and process information about risk decisions is complex and contested, and the implications this has for science communication in general are discussed elsewhere (e.g. Jamieson et al., 2017; National Academies of Sciences, Engi- 
neering, and Medicine, 2017). However, the headline messages that have emerged from several decades of human and behavioural research are neatly summarised by Cormick (2014) (Fig. 3):

1. 'when information is complex, people make decisions based on their values and beliefs';

2. 'people seek affirmation of their attitudes or beliefs, no matter how strange those views are'. This tendency means that individuals will reject information or evidence that are counter to those attitudes and beliefs (Kahan et al., 2010); the fact that new information consistent with one's beliefs is more easily seen as reliable and informative than information that discredits one's initial beliefs explains why beliefs change very slowly and are quite enduring in the face of contrary evidence (Nisbett and Ross, 1980).

3. 'people most trust those whose values mirror their own'. They tend to look to others around them for social clues on how to act, which can either accentuate or decrease social acceptance of the risk of a given issue (Kahan et al., 2010). As a consequence, individuals generally make more risky or extreme decisions as part of a group than as an individual;

4. 'attitudes that were not formed by logic or facts, are not influenced by logical or factual arguments';

5. 'public concerns about contentious science are almost never about the science - and scientific information therefore does little to influence these concerns.'

The notion that logical and factual arguments may be subordinate to value judgements and instinctive thinking in determining how people make sense of technically complex issues has important implications for how the geoscience community conveys its science to the public. After all, conventionally, geoscientists tend to build communication strategies around conveying clear, simple explanations of the technical detail. They do so because that is what geoscientists have been trained to do, because it is that technical know-how that defines their own understanding of the problem, and because other crucial stakeholders - regulators, engineers, planners and lawyers - demand it.

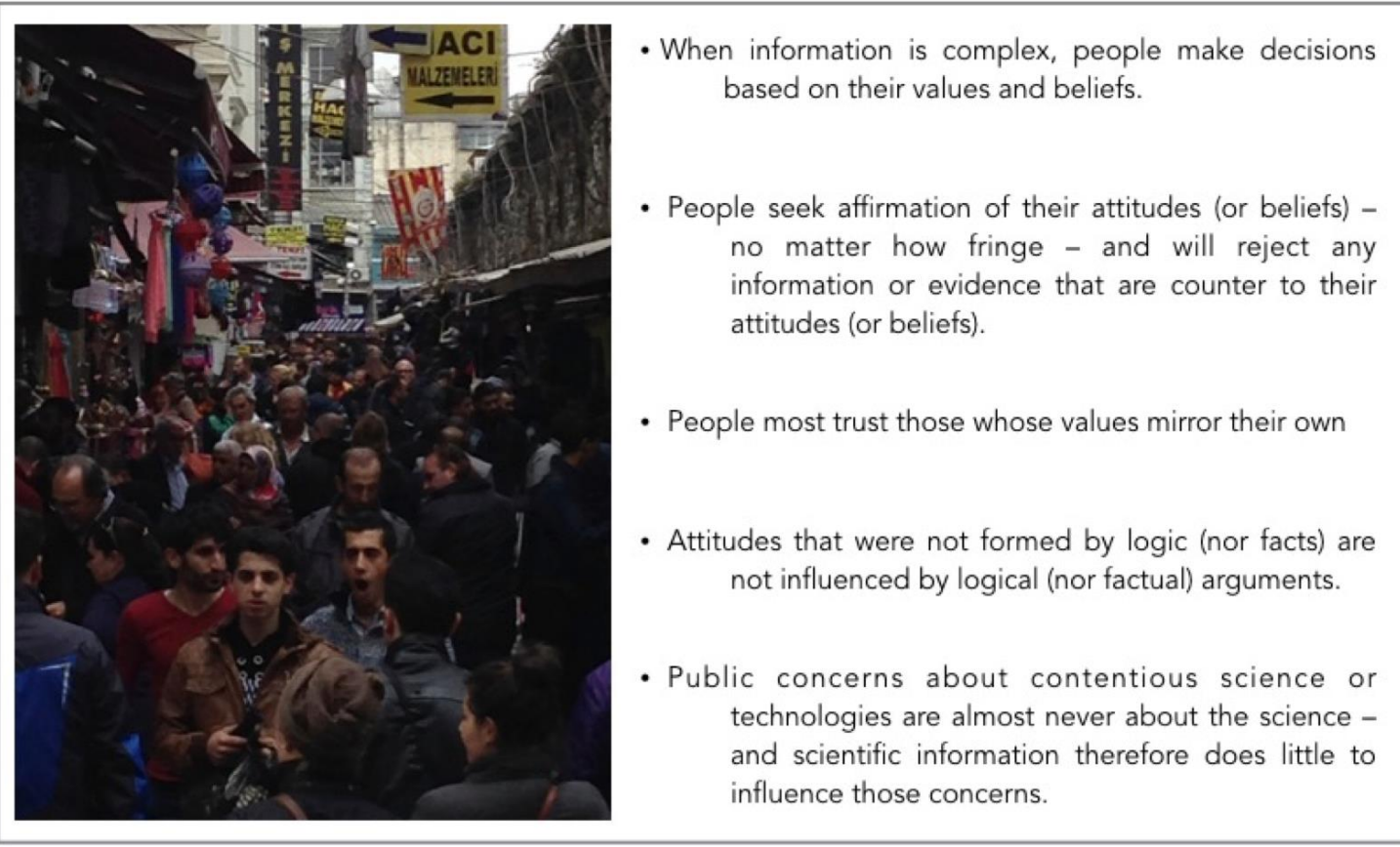

Figure 3: Social science research highlights a few headline messages of how people make decisions about complex and contested environmental concerns (after Cormick, 2014). 


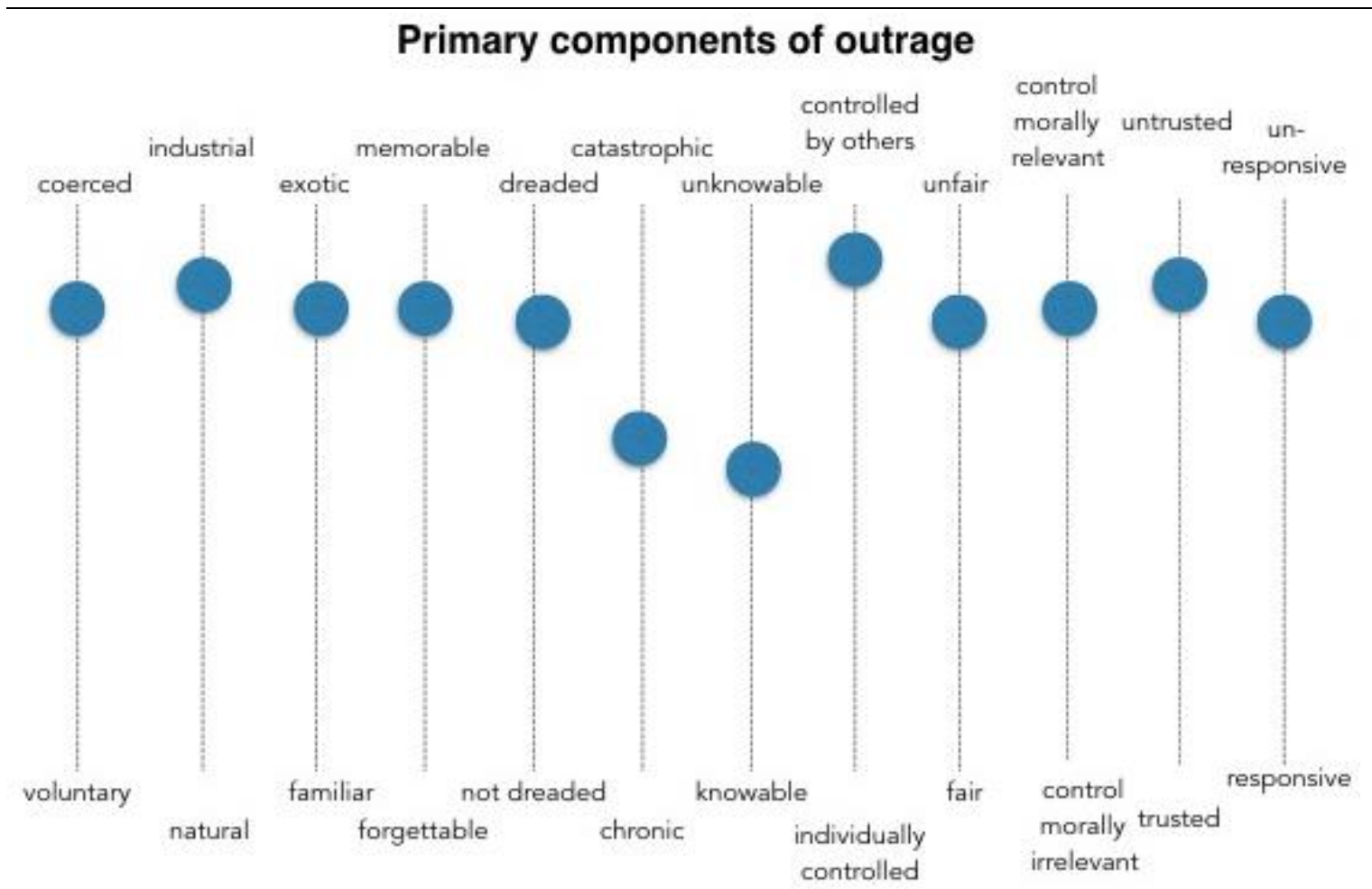

Figure 4: In the context of community conflicts, Sandman (1993) argues that 'risk' is a product of 'hazard $x$ outrage'. Reducing risk can be achieved by lowering outrage through adjusting the levels of the primary components of community anxiety.

But marshalling the scientific facts, illustrating them with simple graphics, and explaining them uncluttered by jargon, seems unlikely to add ress public concerns:

'It is not enough to assure that scientifically sound information - including evidence of what sci-entists themselves believe - is widely disseminated: cultural cognition strongly motivates individuals - of all worldviews - to recognize such information as sound in a selective pattern that reinforces their cultural predispositions. To overcome this effect, communicators must attend to the cultural meaning as well as the scientific content of information' (Kahan et al., 2010, p.23).

\subsection{Risk = Hazard $x$ Outrage}

Understanding the social and cultural construction of risk is recognised to be at the heart of community-centred participatory approaches to disaster risk reduction. It is a notion rooted strongly in the psychometric model of risk per- ception (Fischhoff et al., 1978; Slovic, 1987 and 1989; Slovic et al., 1991; Fischhoff, 1995), which deconvolves the composite public view of 'risky' scientific issues. The 'psychometric' risk paradigm has been widely applied by Sandman (1987, 1989, and 1993), who contends that most local environmental controversies comprise two competing frames. The first is a technical framing of the problem, involving arguments about the scientific analysis of the hazards that are perceived to threaten a community. The second relates to the social context within which those hazards exist and the processes by which a community's anxieties fuels collective anger. According to Sandman (1993), that community anger is rooted in a range of concerns - including trust, control, voluntariness, dread, and familiarity - which he collectively terms 'ou trage factors' (Fig. 4).

Sandman (1993) contends that when the experts and the public disagree about the technical aspects (such as the magnitude of a particular threat or its probability of occurrence), the experts are 
more likely to be correct. And yet, although scientists readily point out how the public often misperceives the hazard, they rarely acknowledge that they themselves pay little attention to that component of the perceived risk that is socially constructed.

'The experts, when they talk about risk, focus on hazard and ignore outrage. They therefore tend to overestimate the risk when the hazard is high and the outrage is low, and underestimate the risk when the hazard is low and the outrage is high - because all they are doing is looking at the hazard. The public, in precise parallel, focuses on outrage and ignores hazard. The public, therefore, overestimates the risk when the outrage is high and the hazard is low, and underestimates the risk when the outrage is low and the hazard is high' (Sandman, 1993, p.8).

The public's concerns - the social risk - is frequently dismissed by scientific experts as being irrational, unfounded or manipulated, even though it is evident from community protests that the resulting anxiety, fear and anger is arguably more tangible and measureable than the underlying hazard. In the context of community conflicts, Sandman suggests that the technical view of risk as a product of 'hazard $\mathrm{x}$ vulnerability' is more usefully reformulated as being a product of 'hazard x outrage'. This, in turn, sets the template for risk communication strategies.

'Two things are true in the typical risk controversy: People overestimate the hazard and people are outraged. To decide how to respond, we must know which is mostly cause and which is mostly effect. If people are outraged because they overestimate the hazard, the solution is to explain the hazard better. But if they overestimate the hazard because they are outraged, the solution is to figure out why they are outraged - and change it.'

\subsection{Risk Dialogues and Honest Brokers}

'... public participation measures are probably the most effective means to create awareness of potential disasters, to enhance trust in public authorities, and to encourage citizens to take more personal responsibility for protection and disaster preparedness. It will be a major challenge for risk management and also an important research topic for future research to understand people's responses to natural hazards as well as a combination of natural and technological hazards and to design the most appropriate measures for effective risk communication, stakeholder involvement, and emergency preparedness' (Wachinger et al., 2013).

An alternative approach to conventional risk message model of communication is the "risk dialogue model", which is based on the belief that the diverse expertise of mix of civil society actors must be systematically anchored if a relevant solution to reduce vulnerability is to be found (Demeritt and Norbert, 2014). Engaging with the wider civil society in a more particip atory way about earthquake threats means framing seismic risk communication not simply as the conventional one-way transfer of information from the technical expert to the 'end user', but also as a two-way exchange with stakeholder groups about what concerns them. In short, paraphrasing Latour (1994), it requires a mind set shift from conveying 'matters of fact' to developing dialogues around 'matters of concern', recognizing that shared rather than unidirectional flows of information are more likely to promote knowledge and attitude change (Stewart and Lewis, 2017). Scientific and technical information are necessary for this process, but are not the sole basis on which decisions or actions are made. When accessible scientific information about a contested scientific issue is presented in well-organized social spaces in which ordinary people can form and express their opinions, the public can actively participate in scientific decision making:

'It appears that people understand some things quite well, although their path to knowledge may be quite different from that of the technical experts... given an atmosphere of trust in which both experts and lay persons recognize that each group may have something to contribute to the discussion, exchange of information and deepening of perspectives may well be possible' (Slovic, 1985, p.170).

Whether directed at the public or at policy makers, more effective communication emerges from participatory engagement and dialogue 
with individuals and communities (Wachinger et al., 2012).

Participation processes allow the public to gain knowledge and personal agency with respect to risks and protective measures, and authorities to gain knowledge from the "lay experts"/ the public and to collect ideas for measures that are effective for the given population. Individuals and communities can be risk amplifiers or inhibitors. Thus, as well as gauging the intrinsic vulnerability of those living in hazard-prone settings, collective conversations provide the expert with a valuable information archive. These dialogues can reveal a social memory of past events and highlight how preventative measures may be built into traditional practices and vernacular architecture. Finally, a shared responsibility for solutions in such a dialogue situation can also promote the social implementation of them.

Yet, despite its apparent benefits, a more participatory approach raises ethical dilemmas for a geoscientist, not least of which is the potential drift away from being a neutral mediator of independent knowledge to a participant that is engaged with, or perhaps even embedded in, community concerns. The scientist as an 'advocate' or even 'activist' for a specific course of action is one that many - experts and nonexperts alike - are uncomfortable with. In distinguishing different 'kinds' of scientist, Pielke (2007) highlights the important role of the 'honest broker' - the specialist who can integrate stakeholder concerns with available scientific knowledge to open up and inform a range of options. Drawing on the faulty communications and their epistemological roots during the Tuhoku and Fukishima catastrophe, Lacassin and Lavelle (2016) highlight the responsibility of communicating uncertainties through such 'honest brokers'. According to the authors, they need not only to focus on the decision-relevant elements of that communicated uncertainties, but also uncover the uncertainties that scientists fail or avoid to mention because of dominant communication paradigms, arguing that:

'... to promote real democratic and open debate and choices, [scientists] have the responsibility to com- municate and properly explain all uncertainties and unknowns to the technical and political sphere as well as to the rest of the society' (Lacassin and Lavelle, 2016, p.57).

As honest brokers, effective geoscience communication becomes not simply a case of securing public acceptance, but, rather, of securing public trust. It is arguably more important to build trust than to build technical understanding because trust is used by people as a surrogate tool - a cognitive shortcut - for reducing the complexity of scientific information. And it is that trust that will be crucial later if warnings and other types of vital information are to be taken seriously during an emergency (Wachinger et al., 2013). Those scientific brokers who genuinely engage with affected communities are likely to have a particularly privileged place in the deliberative process because, in addition to their grasp of technical complexity, they will be afforded a high degree of public trust. Yet that elevated degree of influence, and the anticipated co-production of knowledge that accompanies a communitycentred approach, may make many geoscientists anxious that their much valued independence will be compromised.

\section{CONCLUSIONS}

The ethical responsibility of scientists is the communication of balanced factual information, yet the relative prominence given to those facts is crucial. To convey a scientific message in a way that gains wide acceptance requires a simplified message stripped of the usual technical caveats. The ethical burden that this places on the science communicator as an honest broker of knowledge is obvious. The climate science communicator Stephen Schneider dubbed it the 'double ethical bind', noting that 'Each of us has to decide what the right balance is between being effective and being honest. I hope that means being both' (Schneider, 2002, p.498).

The challenge for those working in disaster risk communication is how to convey what they know honestly and effectively to those people who can benefit from that knowledge. In terms of the former, it requires hazard scientists to better understand the social psychology of how 
people receive and process information, and in doing so learn how best to frame the intricacies, uncertainties and limitations of their intricate technical science in ways that are more easily grasped by lay audiences. In universities and research institutes it will be crucial to train the next generation of geoscientists in the science and art of communication, being more journalistic and media-savvy in the way we communicate, and more imaginative in exploring new communication channels, such as webbased platforms, social media. The new reality is that in times of the crisis factual scientific informations can be quickly (minutes to hours) transmitted through social media (e.g. Twitter, Facebook), thereby helping people to appreciate the geophysical understanding of an ongoing natural event. In the same way, however, misinformation or misconceived facts can equally prominently be instantly relayed, meaning that public trust in honest scientific brokers must be maintained. For this reason, alongside the obvious appeal of new, remote mobile technologies and digital communications, face-to-face encounters will be critical for effective community-centred disaster dialogues. In those encounters, geoscientists should expect to meet the public in their own community spaces - in schools, places of worship, civic halls and social clubs. In addition, deliberative formats such a 'Reallabore' (Marquardt and West, 2016), science shops (Schlierfs and Meyer, 2013) or various formats of informal, dialogue-oriented citizen participation (Kamlage et al., 2018) are important forums where more direct two-way communication approaches between different stakeholders can take place.

But as well as being more effective, geoscientists need to better appreciate that their seismic risk communications are undertaken in contested socio-political contexts and bring ethical dilemmas. The expert technical knowledge of the earthquake geoscientist may be afforded a heightened degree of trust by those individuals and communities most at risk, but that brings responsibility. Ironically, the more effectively a potential seismic threat is communicated by the geoscientist, the more that scientific message will be normalized into the complex, chaotic and contested discourses of daily life. Partici- patory-based engagement strategies anticipate technical experts taking account of these local socio-cultural, emotional and even political dimensions of risk in working directly with vulnerable communities. In such circumstances, scientific risk messages can become hijacked by or assimilated into social, economic and political controversies. The challenge for those working at the contested frontline of seismic risk communications will be balancing the ethical binds that continue to constrain us in our role as honest brokers

\section{ACKNOWLEDGEMENTS}

All three authors gratefully acknowledge the financial support of the EU Marie Curie Initial Training Networks programme 'ALErT' (Anatolian pLateau climate and tectonic hazards) and IS was additionally supported by the NERC-ESRC-AHRC Global Challenges Research Fund project 'Research for Emergency Aftershock Forecasting' (REAR). We thank David Mogk and an anonymous reviewer for constructive comments that improved the manuscript, and to Giuseppe Di Capua for supporting the paper through the reviewing process.

\section{REFERENCES}

Alexander D.E. (2010). The L'Aquila earthquake of 6 April 2009 and Italian Government policy on disaster response. Journal of Natural Resources Policy Research, 2(4), 325-342.

Alexander D.E. (2014). Communicating earthquake risk to the public: the trial of the "L’Aquila Seven". Natural Hazards, 72(2), 1159-1173.

Armijo R., Meyer B., Hubert A., and Barka A. (1999). Westward propagation of the North Anatolian fault into the northern Aegean: Timing and kinematics. Geology, 27(3), 267270.

Baudoin M.A., Henly-Shepard S., Fernando N., Sitati A., and Zommers Z. (2016). From topdown to "community-centric" approaches to early warning systems: exploring pathways to improve disaster risk reduction through community participation. International Journal of Disaster Risk Science, 7(2), 163-174. 
Bendito A. and Barrios E. (2016). Convergent agency: Encouraging transdisciplinary approaches for effective climate change adaptation and disaster risk reduction. International Journal of Disaster Risk Science, 7(4), 430-435.

Bohnhoff M., Bulut F., Dresen G., Malin P.E., Eken T., and Aktar M. (2013). An earthquake gap south of Istanbul. Nature Communications, 4.

Burns T.W., O'Connor D.J. and Stocklmayer S.M. (2003). Science Communication: a contemporary definition. Public Understanding of Science, 12, 183-202.

Clancey G. (2006). Earthquake Nation. The Cultural Politics of Japanese Seismicity, 1868-1930. Berkeley, CA: University of California Press.

Cormick C. (2014). Community Attitudes Towards Science and Technology in Australia. CSIRO, 26p.

Demeritt D. and Nobert S. (2014). Models of best practice in flood risk communication and management. Environmental Hazards, 13(4), 313-328.

DeVasto D., Graham S.S. and Zamparutti L. (2016). Stasis and Matters of Concern: The Conviction of the L'Aquila Seven. Journal of Business and Technical Communication, 30(2), 131-164.

Di Capua G. and Peppoloni S. (2014). Geoethical aspects in the natural hazards management, pp. 59-62. In: Lollino G., Arattano M., Giardino M., Oliveira R., Peppoloni S. (Eds.), Engineering Geology for Society and Territory - Volume 7, Education, Professional Ethics and Public Recognition of Engineering Geology, XVII, 274 p., Springer, ISBN : 978-3-319-09302-4.

Drake J.L., Kontar Y.Y., Eichelberger J.C., Rupp S.T., and Taylor K.M. (Eds.) (2015). Communicating Climate-Change and Natural Hazard Risk and Cultivating Resilience: Case Studies for a Multi-disciplinary Approach, Vol. 45, Springer.

Dolce M. and Di Bucci D. (2014). Risk management: roles and responsibilities in the decision-making process. In: Wyss M. and Peppoloni S. (Eds.), Geoethics: ethical challenges and case studies in Earth Sciences, 450 p., Elsevier, Waltham, Massachusetts, ISBN: 9780127999357.
Eraybar K., Okazaki K. and Ilki A. (2010). An exploratory study on perceptions of seismic risk and mitigation in two districts of Istanbul. Disasters, 34(1), 71-92.

Erdik M., Şeşetyan K., Demircioğlu M., Hancilar U. and Zülfikar C. (2011). Rapid earthquake loss assessment after damaging earthquakes. Soil Dynamics and Earthquake Engineering, 31(2), 247-266.

Erdik M. (2013). Earthquake risk in Turkey. Science, 341, 72 .

Fischhoff, B., (1995). Risk perception and communication unplugged: twenty years of process, Risk Analysis, 15, 137-145.

Fischhoff B., Slovic P., Lichtenstein S., Read S., and Combs B. (1978). How safe is safe enough? A psychometric study of attitudes towards technological risks and benefits. Policy Sciences, 9, 127-152.

Fischhoff B. and Davis A.L. (2014). Communicating scientific uncertainty. Proceedings of the National Academy of Sciences of the United States of America, 111, 13664-13671.

Geschwind C.-H. (1997). 1920s Prediction Reveals Some Pitfalls of Earthquake Forecasting. Eos, Vol. 78, (38), 401-412.

Geschwind C.-H. (2001). California Earthquakes: Science, Risk, and the Politics of Hazard Mitigation. Baltimore and London: Johns Hopkins University Press.

Gibson M. and Gökşin Z.A. (2016). Neighbourhood Regeneration in Istanbul - from Earthquake Mitigation to Planned Displacement and Gentrification. International Planning History Society Proceedings, 17(2).

Green R.A. (2008). Unauthorised Development and Seismic Hazard Vulnerability: a study of squatters and engineers in Istanbul, Turkey. Disasters, 32(3), 358-376.

Güngrmüş Z., Karabulutlu E.Y. and Yıldız E., (2012). Determining the knowledge and behavior of the individuals about earthquake preparedness at home in Turkey. HealthMED, 6 (1), 232-237.

Hall S.S. (2011). Scientists on Trial: At Fault? Nature, 477 (14 September), 264-9.

Hori T., Pinar A., Necmioglu O., Hori M. and Nishizawa A. (2017). Special issue "The next Marmara earthquake: disaster mitiga- 
tion, recovery, and early warning”. Earth, Planets and Space, 69(1), 65.

Ickert J. and Stew art I.S. (2016). From geoscientific "matters of fact" to societal "matters of concern": a transdisciplinary training approach to communicating earthquake risk in Istanbul (Turkey). Natural Hazards and Earth System Sciences, 16(1), 1-1.

Islam T. and Sakızlığlu B. (2015). The making of, and resistance to, state-led gentrification in Istanbul, Turkey. Global gentrifications: Uneven development and displacement, 245.

Ismail-Zadeh A.T., Cutter S.L., Takeuchi K. and Paton D. (2017). Forging a paradigm shift in disaster science. Natural Hazards, 86(2), 969988.

Jamieson K.H., Kahan D., and Scheufele D.A. (Eds.) (2017). The Oxford Handbook of the Science of Science Communication, Oxford University Press.

Joffe H., Rossetto T., Solberg C., and O'Connor C. (2013). Social representations of earthquakes: A study of people living in three highly seismic areas. Earthquake Spectra, 29(2), 367-397.

Jord an T.H. (2013). Lessons of L'Aquila for operational earthquake forecasting. Seismological Research Letters, 84, 1, 4-7.

Kahan D.M., Jenkins-Smith H. and Braman D. (2011). Cultural cognition of scientific consensu s. Journal of Risk Research, 14(2), 147174.

Kamlage J.H. and Nanz P. (2017). Crisis and participation in the European Union: energy policy as a test bed for a new politics of citizen participation. Global Society, 31(1), pp. 65-82.

Kamlage J.-H., Richter I., and Nanz P. (2018). An den Grenzen der Bürgerbeteiligung: Informelle dialogorientierte Bürgerbeteiligung im Netzausbau der Energiewende. In: Handbuch Energiewende und Partizipation, pp. 627-642, Springer.

Karaman O. (2008). Urban pulse - (re)making space for globalization in Istanbul. Urban Geography, 29(6), 518-525.

Karaman O. (2013). Urban renewal in Istanbul: Reconfigured spaces, robotic lives. International Journal of Urban and Regional Research, 37(2), 715-733.

Karanci N. (2013). Facilitating community participation in disaster risk management: Risk perception and preparedness behaviours in
Turkey. In: Joffe H., Rossetto T. and Adams J. (Eds.), Cities at Risk, Springer Netherlands, 93-108.

Kelman I. and Glantz M.H. (2014). Early warning systems defined. In: Reducing disaster: early warning systems for climate change, Springer Netherlands, 89-108.

Kuyucu T. (2014). Law, Property and Ambiguity: The Uses and Abuses of Legal Ambiguity in Remaking Istanbul's Informal Settlements. International Journal of Urban and Regional Research, 38(2), 609-627.

Lacassin R. and Lavelle S. (2016). The crisis of a paradigm. A methodological interpretation of Tohoku and Fukushima catastrophe. Earth-Science Reviews, 155, 49-59.

Latour B. (2004). Why has critique run out of steam? From matters of fact to matters of concern. Critical Inquiry, 30 (2), 225-248.

Liverman D.G. (2008). Environmental geoscience: communication challenges. In: Liverman D. (ed.), Communicating Environmental Geoscience, Geological Society, London, Special Publications, 305(1), 197-209.

Le Pichon X., Chamot-Rooke N., Rangin C. and Sengör A.M.C. (2003). The North Anatolian fault in the Sea of Marmara. Journal of Geophysical Research: Solid Earth, 108(B4).

Marquardt E. and West C. (2016). Co-Produktion von Wissen in der Stadt. Reallabor "Urban Office-Nachhaltige Stadtentwicklung in der Wissensgesellschaft" an der Universität Heidelberg. Technikfolgenabschätzung-Theorie Und Praxis, 25(3), 26-31.

Marzocchi W. (2012). Putting science on trial. Physics World, 25(12), 17.

Michaels D. (2006). Manufactured uncertainty. Annals of the New York Academy of Sciences, 1076(1), pp.149-162.

Michaels D. and Monforton C. (2005). Manufacturing uncertainty: contested science and the protection of the public's health and environment. American Journal of Public Health, 95(S1), pp.S39-S48.

Mucciarelli M. (2014). Some comments on the first degree sentence of the "L'Aquila trial". In: Wyss M. and Peppoloni S. (Eds.), Geoethics: ethical challenges and case studies in Earth Sciences, 450 p., Elsevier, Waltham, Massachu setts, ISBN: 9780127999357. 
National Academies of Sciences, Engineering, and Medicine (2017). Communicating Science Effectively: A Research Agenda. Washington, DC: The National Academies Press, doi: $10.17226 / 23674$.

Nisbet M.C. (2009). Communicating climate change: Why frames matter for public engagement. Environment: Science and Policy for Su stainable Development, 51, 12-23.

Nisbet M.C. and Mooney C. (2009). Framing science. Science, 316.

Nisbett R.E. and Ross L. (1980). Human inference: Strategies and shortcomings of social judgment. Prentice-Hall, Englew ood Cliffs, NJ.

Oral M., Yenel A., Oral E., Aydin N. and Tuncay T. (2015). Earthquake experience and preparedness in Turkey. Disaster Prevention and Management, 24(1), 21-37.

Oreskes N. and Conway E.M. (2011). Merchants of doubt: How a handful of scientists obscured the truth on issues from tobacco smoke to global warming. Bloom sbury Publishing USA.

Oreskes N. (2015). How Earth Science Has Become a Social Science. Historical Social Research 40, 2, 246-270.

Owen R., Macnaghten P. and Stilgoe J. (2012). Responsible research and innovation: From science in society to science for society, with society. Science and Public Policy, 39(6), pp.751-760.

Özerdem A. (1999). Tiles, taps and earthquakeproofing: lessons for disaster management in Turkey. Environment and Urbanization, 11(2), 177-180.

Palm R. (1998). Urban earthquake hazards: the impacts of culture on perceived risk and response in the USA and Japan. Applied Geography, 18(1), pp.35-46.

Palm R. and Hodgson M.E. (1992). After a California Earthquake: Attitude and Behavior Change. The University of Chicago Press: Chicago.

Parsons T., Toda S., Stein R.S., Barka A. and Dieterich J.H. (2000). Heightened odds of large earthquakes near Istanbul: an interaction-based probability calculation. Science, 288 (5466), 661-665.

Pidgeon N., Demski C., Butler C., Parkhill K. and Spence A. (2014). Creating a national citizen engagement process for energy policy. Proceedings of the National Academy of Sciences, 111 (Supplement 4), pp.1360613613.

Pielke Jr R.A. (2007). The honest broker: making sense of science in policy and politics. Cambridge University Press.

Rossetto T., Joffe H. and Solberg C. (2011). A different view on human vulnerability to earthquakes: lessons from risk perception studies. In: Spence R., So E. and Scaw thorn C. (Eds.), Human Casualties in Earthquake, Springer Netherlands, 291-304.

Rustemli A. and Karanci N.A. (1999). Correlates of earthquake cognitions and preparedness behaviour in victimised population. The Journal of Social Psychology, 139 (1), 91-101.

Sandman, P.M. (1987). Risk communication: facing public outrage, EPA J., 13, 21-22.

Sandman, P. M. (1989). Hazard versus outrage in the public perception of risk, in: Covello, V.T. (Editor). Effective Risk Communication, New York: Putnam Press, 45-49.

Sandman P.M. (1993). Responding to community outrage: strategies for effective risk communication. American Industrial $\mathrm{Hy}-$ giene Association, Fairfax, Va.

Schlierf K. and Meyer M. (2013). Situating knowledge intermediation: Insights from science shops and knowledge brokers. Science and Public Policy, 40(4), 430-441.

Schlosser P. and Pfirman S. (2012). Earth science for su stainability. Nature Geoscience, 5 (9), 587-588.

Schneider S.H. (2002). Keeping out of the box. American Scientist, 90 (Nov-Dec), 496-498.

Scolobig A., Prior T., Schröter D., Jörin J. and Patt A. (2015). Tow ards people-centred approaches for effective disaster risk management: Balancing rhetoric with reality. International Journal of Disaster Risk Reduction, 12, pp.202-212.

Shah H.C. (2006). The last mile: earthquake risk mitigation assistance in developing countries. Philosophical transactions - Series A, Mathematical, physical, and engineering sciences, 364(1845), 2183-2189.

Slovic P. (1985). Informing and Educating the Public about Risk. Disaster Research Report, Oregon, 80-85. 
Slovic P. (1987). Perception of risk. Science, 236 (4799), 280-285.

Slovic P. (ed.) (2000). The Perception of Risk. Earthscan, London.

Slovic P., Flynn J.H. and Layman M. (1991). Perceived risk, trust, and the politics of nuclear w aste. Science, 254 (5038), 1603-1607.

Solberg C., Rossetto T. and Joffe H. (2010). The social psychology of seismic hazard adjustment: re-evaluating the international literature. Nat. Hazards Earth Syst. Sci., 10, 1663-1677.

Stein R.S., Barka A.A. and Dieterich J.H. (1997). Progressive failure on the North Anatolian fault since 1939 by earthquake stress triggering. Geophysical Journal International, 128(3), 594-604.

Stew art I.S. and Nield T. (2013). Earth stories: context and narrative in the communication of popular geoscience. Proceedings of the Geologists' Association, 124(4), 699-712.

Stewart I.S. and Lewis D. (2017). Communicating contested geoscience to the public: Moving from 'matters of fact' to 'matters of concern'. Earth-Science Reviews, Vol. 174, pp.122-133.

Tekeli-Yeşil S., Dedeoğlu N., Braun-Fahrlaender C. and Tanner M. (2010a). Factors motivating individuals to take precautionary action for an expected earthquake in Istanbul. Risk Analysis, 30(8), 1181-1195.

Tekeli-Yeşil S., Dedeoğlu N., Tanner M., Braun-Fahrlaender C. and Obrist B. (2010b). Individual pre-paredness and mitigation actions for a predicted earthquake in Istanbul. Disasters, 34(4), 910-930.

Tekeli-Yeşil S., Dedeoğlu N., Braun-Fahrlaender C. and Tanner M. (2011). Earthquake awareness and perception of risk among the residents of Istanbul. Natural Hazards, 59(1), 427-446.

UNISDR (2015). The Sendai Framework for Disaster Risk Reduction 2015-2030, United Nations International Strategy for Disaster Reduction, http:/ / www.preventionweb.net / files/ 43291_send aiframew orkford rren.pdf (accessed 31 January 2018).

Unsal B.O. (2015). State-led Urban Regeneration in Istanbul: Power struggles between interest groups and poor communities. Housing Studies, 30(8), 1299-1316.
Wachinger G., Renn O., Begg C. and Kuhlicke C. (2013). The Risk Perception Paradox Implications for Governance and Communication of Natural Hazards. Risk Analysis, 33, No. 6.

Witte K. and Allen M. (2000). A meta-analysis of fear appeals: Implications for effective public health campaigns. Health Education \& Behavior, 27(5), 591-615.

Wood M.M., Mileti D.S., Kano M., Kelley M.M., Regan R. and Bourque L.B. (2011). Communicating Actionable Risk for Terrorism and Other Hazards. Risk Analysis, 32, 601615.

Yeo M. (2014). Fault lines at the interface of science and policy: Interpretative responses to the trial of scientists in L'Aquila. EarthScience Review s, 139, 406-419. 